\title{
Effectiveness of Social Skills Training, Problem Solving Method to Reduce Behavioral Problems Mentally Retarded Students from Elementary School Boy City of ILAM
}

\author{
Seyed Rahmatallah Musavimoghadam \\ Associate Professor and Head of Department of Islamic Theology Faculty of Medicine \\ University of Medical Sciences, ILAM, Iran
}

\author{
Hamid Nasrallahi \\ Clinical Psychology Graduate Student, University of Science ILAM, Iran. Corresponding Author
}

\author{
Doi:10.5901/mjss.2015.v6n6s6p143
}

\begin{abstract}
Exceptional Children like other human beings who have children of their own human rights. Today research and efforts of scientists the most correct deficiencies and behavior disorders and is focused track. Some of these children have the skills to control and limit their behavior and as a teenager their disabilities, behavior control leading to serious conflicts. Research design was a pretest and posttest. The population for this study included all children with intellectual disability ILAM city and the sample consisted of 20 children, which are chosen randomly and 2 controls and control is divided. The instrument was a questionnaire evaluating teachers' behavior is Rater. To analyze the data in this study, descriptive statistics and inferential statistics (t-dependent) the computer software SPSS is used. Due to the resulting value of $t(3 / 369)$ and 9 degrees of freedom the results showed that social skills training, problem solving method is effective in reducing behavioral problems in children with mental disabilities. $(P>0 / 05)$. The results obtained from this study is that the effects of social skills training, behavioral problems in children with mental disabilities it should be noted if educators and families with the principles of education and psychology of these children and the academic standards, training them to pay not only fatigue and burnout are not. But steadily increasing progress it will be children.
\end{abstract}

Keywords: social skills training, problem solving method, reduce behavioral problems, mentally retarded students, elementary school boy, ILAM.

\section{Introduction}

To succeed and thrive in this world and deal effectively with many of the problems that we are facing a special set of skills is required. ELKNOR and BALBIN (2007) social skills, as socially acceptable behavior pattern described, the students to strengthen the business community and acceptance and to avoid the thorny situations and helps people, positive feedback received social environment and to avoid negative feedback and facilitate interpersonal relationships. Children with different disabilities often in appropriate social interactions with peers and adults in various situations, has problems. They often lack the social skills necessary for positive interactions and are targeted. A significant number of students, especially students with mental disabilities due to cognitive limitations (in terms of perception, memory and attention) do not act in accordance with their age and learning complex concepts are in trouble. The students given the limited capacity of learning in abstract terms and the inability of the lessons that implicitly done we need to teach social skills, in order to acquire the necessary skills, social life, and reduce behavioral problems (Soleimani, 2011). Several studies have shown that a lack of social skills have a negative impact on academic performance. Ray and Elliott (2006) interpersonal, emotional and behavioral aspects of the problem; MERILL and GAMPLAY (1998), exacerbates the problems of learning, the child's progress and eventually lead to undesirable consequences during schooling, students can reduce compatibility, students with disabilities in all the crops. Also students who are not able to fulfill the demands of the classroom unwelcome feelings of inadequacy, anxiety, decreased motivation and behavioral inconsistencies produce. Thus social skills training, one of the most useful software which all students of personal accomplishment and help the community and in view of the nature of the objective and that is tangible, mentally retarded students can also take advantage of such training programs they ( Soleimani, 2011). KALEB and Hanley (2003) many definitions, social skills cited. Social skills often as a complex set of skills is taken into account including communication, problem solving and decision-making, assertiveness, interaction with peers and groups and managed. Matson et al (2003) social skills, 
behaviors as can be observed, measured and defined, independence, acceptability and quality of life improve. These skills to compromise specificity and function are important in normal and impaired social skills, closely mental disorders and behavioral problems are related. To define the functional impairment careful manner and are not easy. Too often the problems are considered abnormal behavior whereas the normal term, the concept of middle, moderate and normal (khanzadeh, firouzjah \& safikhani, 2009). Social skills training skills including that of persons for meaningful interpersonal relationships communication, accurate and clear accurate assessment self and reward to help the adaptive behavior. The results of this training, suggests that in the ability to manage anger BARRA et al (2002) (Toyserkaniravi, 2000). the reduction of violent behavior, TAGLASI and ROTMAN (2001), aggression PRIZ et al (1994), social anxiety and social behavior, (Lieberman, 1989; FOROUTAN, 2004), better social skills and aggression (BEARMAN and Forman, 1984), depression HAUSAN \& BLARKE, 1984; FOROUTAN, 2004) and to reduce crime, (Steps, 1979; FOROUTAN, 2004) has been effective. Also TOYSERKANI (2009) in their study the effects of social skills training based on the story, the symptoms of conduct disorder in children concluded that teaching these skills based on the story, reduce the symptoms of conduct disorder in their subjects (Toyserkaniravi, 2000). The results TABAEIAN (2008) based on the effects of social skills training, increasing social skills and improve relations with the public the children acquired attention deficit disorder/hyperactivity suggests that the training increased social skills and improve relationships with everyone in the experimental group. Also the results of paired comparisons showed that a combination of education, social skills (direct instruction to the child and parental education) with drug therapy which was presented to the experimental group, the increase in social skills improve relationships with everyone far more than the result of social skills training through direct instruction to children with drug therapy the experimental group was given (Tabatabaian, 2008). BEHPAZHOUH et al (2008) in their study in assessing the effectiveness of social skills training the students are blind to the conclusion that self-esteem, social skills training to improve self-esteem and blind students in the experimental group was significantly more effective. These findings indicate that the implementation of this program is to blind students in the experimental group has helped in interaction with their peers with high self-esteem of their behavior (Behpazhouh, KHanjani, Heydari \& SHokouhiyekta, 2008). In another study, BEIRAMI and ORADI (2007) the effects of social skills training, the social competence of their students, and their results showed that social skills training, attitude, stress management, and improve students' self-efficacy and the change is retained over time, as a result the education, social competence improved (Beyrami \& Moradi, 2007). SOKHANDANTOMACH (2002) in their study, the subject of assessing the effectiveness of social skills training, behavioral problems, emotional and school children have addressed the issue, and analyze the results of her study, using multivariate analysis of variance (MANOVA) showed that is social skills training, behavioral problems, emotional and school children significantly reduced. Results obtained in this study the effectiveness of social skills training in reducing behavioral problems, and emotional supports children (Sokhandantomach, 2002). Also DEHBOZORGI (1994) in their study in assessing the effectiveness of social skills training adjustment in schizophrenia patients concluded that social relations in the experimental group were significantly increased and the skills to everyday life extension was given (Foroutan, 2004).

\section{Method}

This study for the purpose of application, in terms inference descriptive. The population of this study all the males from first grade to fifth grade the mentally retarded the city of ILAM 2015-2014 school year were enrolled in total. Because of the low number of population research approach to achieving students with behavioral problems the teachers, the students are presented with the action we have number of these students were 25 then for each this number ROTTER questionnaire (form teacher) was completed it was determined that of these 20 patients with behavioral problems (score of 9 or more in the form teacher). The sample size of 20 individual selected (randomly) 10 patients in the experimental group and 10 patients in the control group were placed. In this study who have behavioral problems that is, his scores in behavioral assessment questionnaire ROTTER (form teacher), 9, or greater than 9. In this research, the mentally retarded students who said that, after the implementation of the Wechsler Intelligence tests, LITER and GODINAF learners can be detected and in special schools in the mentally retarded, is studying. Instruments included a questionnaire Michael ROTTER Child Behavior Diagnostic Evaluation Form (teachers and parents): The questionnaire by Michael ROTTER (1967) constructed, and consists of two parents (31 questions) and teachers (30 items) is in this study only the teacher form is used. In the questionnaire, scores range from 0 to 60 range. Score higher than 9 indication of impairment, and a lower score of 9 signs normal. In this study, social skills as an independent variable, is taken into account, the dependent variable, which affects the behavior problems. Boys in this study, is considered as a variable deflator and mental disability, primary students as a control variable this is the first study questionnaire, ROTTER et al (1975) using split method ROTTER questionnaire trust it about 0/89 and through the open trial was conducted on 90 
people for 13 days. Research EHSANMANESH (1993), CARAMI (1994) and YOUSEFI (1999) indicating the validity ROTTER questionnaire, to assess behavioral problems in children in the Iranian culture [Karaminoury \& Moradi, 1995). Introducing students with behavioral problems, the teachers and conduct performance evaluation questionnaire ROTTER about them (pretest) and then collected the questionnaires and scoring, sample question, researchers randomly into two groups, experimental and control groups. Groups over 5 sessions, 45 minutes for 2 weeks, the program "Teaching social skills, problem solving method" participated (Introducing independent variable). With these skills, the token economy to reinforce the desired behavior the students used to be an incentive to reduce their undesirable behavior. The control group received no intervention at this time. 10 days after the training sessions, questionnaires ROTTER teacher teacher (post-test) were distributed. After collecting the questionnaires and scoring again, the data obtained were analyzed.

In this study, descriptive statistics such as the facade, median, mean, standard deviation, variance, maximum, minimum and error deviation, mean and inferential statistics, t-dependent for the analysis of statistical data the software SPSS computer is used.

\section{Finding}

The results can be seen in the following tables.

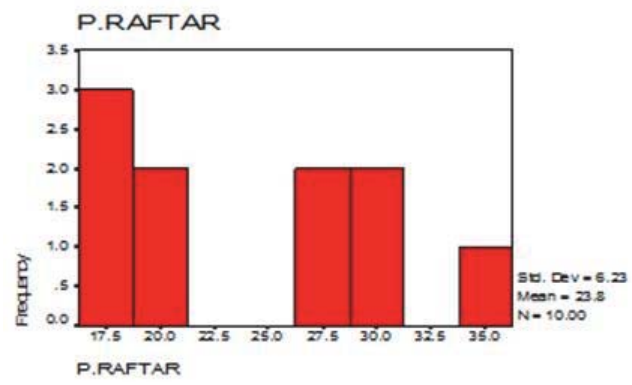

Figure 1: The situation in the control group pretest

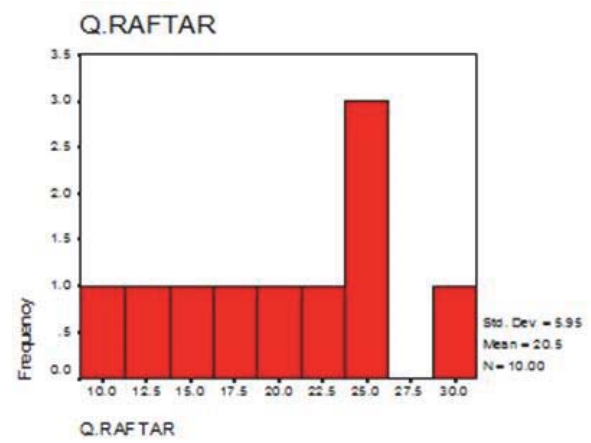

Figure 2: The situation in the posttest control group

Table 1. Descriptive statistics for both the pretest and posttest groups

\begin{tabular}{|l|c|c|c|c|c|c|c|c|}
\hline Status indicator & mean & Middle & Front & variance & maximum & minimum & standard deviation & Deviation error \\
\hline Pretest & $26 / 90$ & 27 & 13 & $10 / 816$ & $116 / 988$ & 43 & $13 / 1$ & $3 / 42$ \\
\hline Posttest & 19 & $19 / 50$ & 15 & $7 / 57$ & $57 / 33$ & 31 & $8 / 1$ & $2 / 39$ \\
\hline
\end{tabular}


Table 2: Comparison of the experimental group in both the pretest and posttest scores of behavioral disorders

\begin{tabular}{|l|c|c|c|c|c|}
\hline Status & mean & Mean difference & df & $t$ & $p$ \\
\hline Pretest & $26 / 90$ & $7 / 90$ & 9 & $3 / 369$ & 0 \\
\cline { 1 - 2 } Posttest & 19 & & 9008 \\
\hline
\end{tabular}

Table 3: Comparison of the control group in both the pretest and posttest scores of behavioral disorders

\begin{tabular}{|l|c|c|c|c|c|}
\hline Status & mean & Mean difference & $\mathrm{df}$ & $\mathrm{t}$ & $\mathrm{p}$ \\
\hline Pretest & $23 / 80$ & $3 / 30$ & 9 & $1 / 472$ & $0 / 175$ \\
\hline Posttest & $20 / 50$ & & & & \\
\hline
\end{tabular}

\section{Discussion}

The 20 participants in social skills training pre-test control group of 10 patients with a mean of 23.8 and a standard deviation of 6.23 and test with average 5/95 and the standard deviation was 5.20 (Figure 1). Group test after test, with mean 0/19 and SD 7/57 and 26/50 pretest mean, and standard deviation was 81/10 (Table 1). As Table 2 shows in terms of groups in the pretest and posttest there is according to the estimated value of $t(3 / 369)$ and a small amount of confidence (0/008) the $0 / 05$ so the hypothesis, based on "social skills training may be effective in reducing behavioral problems in children" is true. As Table 3 shows in the control group, in both the pre-test and Posttest there was no significant difference.

\section{Conclusion}

The present study aimed to evaluate the effectiveness of social skills training, problem solving method to reduce behavior problems in mentally retarded students from elementary school boy city of ILAM with a sample size of 20 individuals a simple random sampling (10 in the experimental group and 10 patients in the control group) was performed. The results showed that social skills training (problem solving) the reduction behavior of the mentally retarded students from elementary school boy there was a significant effect of ILAM. In other words teaching social skills (problem solving) can reduce behavioral problems help students with mental disabilities. These finding research results of SHOR, SPIVAK \& Gordon (1972), as well as results SPIVAK and SHOR (1974) and Mc Carrick and DISS (2000), Greene et al (2004) and Johnson (2001), RIDO, Webster ESTEVATON (2000) who found that problem-solving skills in children to reduce impulsivity Gary and deterring aggression and social skills are impressive consistent ((Shure, Spivack \& Gordon, 1972), (Spivack, Shure, 1974), (Mccarrick-Dix, 2000)) as well as an increase in children's problem-solving scores measured by improvement in behavior ability to raise children delay claims, and improved social behavior associated with ((Janson, 2001), (Reid, Webster-Stratton, 2001), (SHokouhi \& Akram, 2008)). On account of these findings it can be said because of cognitive deficits in individuals with mental retardation, thinking skills, such as problem solving, and decision-making at the school, according to social skills training is essential (Teodoro, Kappler, Rodrigues, de Freitas \& Haase, 2005). Thus social skills training, the students are slow learners and how and with what quality come together and appropriate behaviors and acceptance of their work is necessary. Acquisition of social skills, social development, main axis, forming social relationships the quality of social interactions, social adjustment and mental health of a person is considered (Harji, Sanderz \& Dickson, 1994). One of the features of social skills they are acquired and now, many researchers agree that most social behaviors are learned as children, in unsuitable environments are large, socially undesirable behaviors in (Firouzbakht, 1999). The limitations of this study is that several factors such as class structure, age, experience and attitudes of teachers, admission of students with mental disabilities, the school, family and community, the ability and social problem-solving skills of the students are effective, the important thing is that, likely samples of this study due to the small sample size a good representative for the mentally retarded students in the other provinces do not provide the results can be generalized. So to generalize the results to other students with intellectual disability be done with caution. Based on the results of this study, effect of social skills training, problem solving method to reduce behavior problems mentally retarded students, it can be said that the training had a positive effect in improving their social skills and the impact was effective in reducing behavioral problems in children such that the difference between the means of two groups control difference was significant. So we can conclude social skills training, to help children with mental disabilities has good skills in reducing problem behaviors and skills to achieve the desired behavior and their interactions, behaviors, better and best of show. According to the results obtained from this study and consider the results of studies in the field of 
social skills training and skills necessary to achieve this the following recommendations can be mentioned: 1 . It is recommended that in the preparation of books about social skills, life, earnest effort is required and as possible the content of the books, for children to be easily understood and understanding, so that they too with books shall, without the guidance of teachers as much as possible and understanding and understanding to take advantage. 2. It is recommended that this book as a teaching material, formal like textbooks, students will be included in the curriculum (in addition to the integration of education the skills of the teachers in normal situations more than they use). 3 . It is better to books from primary school the school carried out to education to be taken as a basis. 4. As possible the content of the books dried material and not looking and have more practical. 5. In the context of how the content of the book a scientific, accurate and can be implemented in the schools the teachers in-service training to be held to become more familiar with the contents of this book and as the right to education and offer it to students in action.

\section{References}

Behpazhouh, A. Khanjani, M. Heydari, M. Shokouhiyekta, M. (2008). Evaluate the effectiveness of social skills training on self-esteem blind students, research on mental health Teacher EducationTehran University, No. III.

Beyrami, M. Moradi, A.R. (2007). The effects of social skills training on children's social competence FELNER model, Journal of Tabriz University, No. 4.

Foroutan, KH. (2004). The relationship between social skills and academic achievement and seal third Lamerd County, MA, Islamic Azad University of Shiraz.

Janson, J.L (2001) Preventing conduct problems and increasing social competence in high-risk preschoolers. Dissertation Abstracts International: Section B: The Science and Engineering, 62 (2-B), pp.1085.

HARJI, O. Sanderz, K. Dickson, D. (1994). Social skills in interpersonal communication, translation Khashayar Beigi and Mehrdad Firouzbakht 1999. Tehran: the growth.

Karaminoury, R. Moradi, A.R. (1995).Educational Psychology, Tehran: Iran's publishing company.

Khanzadeh, Firouzjah. Abbasali, H. Safikhani, L. (2009). Measurement and social skills training, special education, No. 86, pp. 16.

Reid, M. J. Webster-Stratton, C. (2001). The incredible years parent, teacher, and child intervention: Targeting multiple areas of risk for a young child with pervasive conduct problem using a flexible, manual zed treatment program. Cognitive and Behavioral Practice, 8 (4), 377-386.

Mccarrick-Dix, P. M. (2000). Violence in the schools. Dissertation Abstracts International Section A: Humanities and Social Sciences, 61 (1-A), pp. 84.

Shokouhi, Y. AKRAM, M. (2008). Parent training problem and its impact on children's behavior, the journal Psychological Science, 22 (150-134).

Shure. M.B. Spivack, G. Gordon, R. (1972). Problem-solving thinking: A preventive mental health program for preschool children. Reading Research and Instruction, 4, 259-273.

Sokhandantomach, R. (2002). Evaluate the effectiveness of social skills training on children's emotional and behavioral problems Gonbad city, MS, University of Isfahan.

Soleimani, M. Behpazhouh, A. Afrouz, GH.A. Lavasani, GH.A. (2010). The effects of social skills training on social adjustment and academic performance of students Slow, special education, numbers 95 and 96, p. 10.

Soleimani, M. (2011). Teaching social skills to children with mental disabilities and provide a new approach to teaching social skills, special education, №. 103, p. 54.

Spivack, G. Shure, M. B. (1974). Social adjustment of young children: A cognitive approach to solning real-life problems. San Francisco: Jossey-Bass.

Toyserkaniravi, M. (2000). The effects of social skills training based on the story of the symptoms of conduct disorder in children, Journal of Family Studies, 13.

Tabatabaeian, R. (2008).Increasing the effectiveness of social skills training, social skills and improving relations with counterparts in children acquired attention deficit disorder / hyperactivity, MA, University of Isfahan.

Teodoro, M.L. Kappler, K.C. Rodrigues, J.L. de Freitas, P.M. Haase, V.G. (2005). The Matson Evaluation of Social Skills with Youngsters (MESSY) and its Adaptation for Brazilian children and adolescents. International Journal of Psychology, 39, 2, 239246. 